\title{
ESTUDO MORFOMÉTRICO COMPARANDO DUAS ALTERNATIVAS DE RECONSTRUÇÃO DA VIA DE EFLUXO VENOSO DO ENXERTO NO MÉTODO PIGGYBACK DE TRANSPLANTE DE FÍGADO
}

\author{
Morphometric study comparing two methods of hepatic venous outflow \\ reconstruction in piggyback liver transplantation
}

\author{
Fabricio Ferreira Coelho', Paulo Celso Bosco Massarollo', Gina Camilo Rocha Silvestre', \\ Henrique Dametto Giroud Joaquim¹, Fabio Pescarmona Gallucci', Fernando Matheus', Rodrigo José de Oliveira', \\ Consuelo Junqueira Rodrigues ${ }^{1}$, Aldo Junqueira Rodrigues Júnior ${ }^{1}$
}

\begin{abstract}
RESUMO
Introdução: A freqüência de complicações do efluxo venoso no transplante de fígado piggyback (Tx) está relacionada com o tipo de reconstrução empregado. Há uma baixa incidência quando são utilizadas as três veias hepáticas (DME) do receptor. No entanto, nessa modalidade, existe redução na eficiência do retorno venoso na fase anepática do Tx. A utilização do óstio das veias hepáticas direita e média (DM) propicia menor constrição da veia cava inferior (VCI). Entretanto, esse benefício só se justifica se a via de efluxo venoso obtida não apresentar restrições anatômicas. Objetivo: Comparar a congruência do perímetro da VCI com o das bocas anastomóticas e dos óstios de drenagem na VCI, obtidos nas modalidades DM e DME. Método: Realizou-se estudo prospectivo morfométrico em 16 cadáveres frescos, aferindo-se o perímetro da VCI (PVCI) e, nas reconstruções DM e DME, o perímetro das bocas anastomóticas (PDM e PDME) e dos óstios de desembocadura na VCI (PoDM e PoDME). A análise estatística foi realizada por meio de análise de variância (ANOVA) para medidas repetidas. Resultado: Os valores de PDME (137,2 $\pm 24,3 \mathrm{~mm} ; \mathrm{p}<0,001), \operatorname{PDM}(123,2 \pm 20,1 \mathrm{~mm} ; \mathrm{p}=0,003)$ e PoDM $(116,6 \pm$ $17,5 \mathrm{~mm} ; \mathrm{p}=0,027)$ foram significantemente maiores do que PVCI $(107,9 \pm 18,8 \mathrm{~mm})$. PDME foi significantemente maior que PDM $(\mathrm{p}=0,004)$ e PoDM ( $\mathrm{p}=0,001)$. Conclusão: A modalidade DM apresenta perímetro maior que o da VCI tanto no sítio de anastomose quanto no óstio de desembocadura na VCI. Em comparação com DME, a modalidade DM apresenta perímetro mais congruente com o da VCI.
\end{abstract}

Descritores: Transplante de Fígado, Anatomia, Veias Hepáticas, Circulação Hepática, Estudo Comparativo, Cadáver.

Instituição:

${ }^{1}$ Laboratório de Anatomia Médico-Cirúrgica (LIM/02), Departamento de Cirurgia da Faculdade de Medicina da USP, São Paulo, SP, Brasil

\footnotetext{
Correspondência:

Dr. Fabricio Ferreira Coelho,

Rua Cardeal Arcoverde, 201 apto. 143

CEP 05407-000 - São Paulo - Brasil

Tel.: 5511 3088-0336/9888-4117

E-mail: ff_coelho@hotmail.com
}

Recebido em: 23.03.2007

Aceito em: 10.04.2007

\section{INTRODUÇÃO}

No transplante hepático ( $\mathrm{Tx}$ ), a reconstrução da via de efluxo venoso deve, idealmente, atingir duas metas principais: a primeira é garantir uma drenagem venosa adequada, evitando as graves conseqüências da congestão aguda do fígado, as quais podem determinar mortalidade de até $24 \%$; a segunda é a manutenção do retorno venoso sistêmico durante o pinçamento da veia cava inferior (VCI) do receptor, necessário para a confecção da anastomose venosa. ${ }^{2,3,4} \mathrm{Na}$ maioria dos métodos de reconstrução empregados, a estratégia utilizada para a obtenção de um desses objetivos implica dificuldades para alcançar o outro.

No método mais clássico de Tx denominado "convencional", a porção retro-hepática da VCI do receptor é ressecada durante a hepatectomia e sua reconstrução é realizada por meio de duas anastomoses términoterminais realizadas acima e abaixo do fígado. ${ }^{5,6}$ Nesse método, obtém-se absoluta preservação da sintopia das vias de drenagem venosa do fígado, sendo que eventuais problemas de bloqueio do efluxo raramente ocorrem, devido principalmente a defeitos técnicos 
na confecção da anastomose na porção supra-hepática da VCI. Por outro lado, o método exige pinçamento da VCI do receptor acima e abaixo do fígado durante o período entre o término da hepatectomia e a revascularização do enxerto, manobra que determina queda de $40 \%$ a $50 \%$ do débito cardíaco e aumento de $75 \%$ a $90 \%$ da resistência vascular periférica., ${ }^{2,8}$

Para evitar essas alterações hemodinâmicas, utiliza-se habitualmente um sistema de circulação extracorpórea com bomba centrífuga durante a fase anepática do Tx convencional que desvia para a veia cava superior o sangue dos territórios da VCI e da veia porta. ${ }^{2,6}$

Ulteriormente, foram desenvolvidos diversos métodos alternativos de Tx que têm em comum a preservação da VCI do receptor, na qual a via de efluxo do enxerto é implantada lateralmente. ${ }^{9}$ Em todos esses métodos, genericamente conhecidos como "piggyback", o pinçamento da VCI do receptor é apenas parcial, permitindo a manutenção do retorno venoso sem necessidade do uso do desvio veno-venoso. ${ }^{4,5,6}$

A essa vantagem do Tx piggyback contrapõem-se diversos relatos de maior incidência de complicações da drenagem venosa do enxerto. ${ }^{7,10,11,12}$ Ducerf et al, ${ }^{13}$ em estudo hemodinâmico, encontraram um gradiente de pressão entre a veia hepática livre e o átrio direto (PVHL-PVC) superior a $3 \mathrm{~mm} \mathrm{Hg}$ em $25 \%$ dos pacientes submetidos a Tx piggyback. Já Cirera et $a l^{14}$ fazem referência à incidência três vezes maior de ascite maciça após o Tx piggyback, quando comparado com o convencional $(9,1 \%$ vs. 3,3\%). Nesse estudo, o gradiente PVHLPVC foi significativamente maior nos casos com ascite, sugerindo uma causa hemodinâmica para essa complicação $\left(10,4 \pm 3,7 v s^{5,6}\right.$ $\pm 4,6 \mathrm{~mm} \mathrm{Hg} ; \mathrm{p}<0,01)$.

A discrepância entre as freqüências relatadas de bloqueio de efluxo venoso no método piggyback parece relacionada, em grande parte, com o tipo de reconstrução empregado. ${ }^{15,16}$ Nos casos em que é realizada anastomose látero-lateral (LL) entre a VCI do enxerto e do receptor, a freqüência dessa complicação varia de zero a $0,7 \%$ em diferentes estudos. ${ }^{1,8}$ Incidência semelhante, variando de zero a $1,2 \%$, é relatada nas reconstruções que utilizam os óstios das três veias hepáticas do receptor (DME). ${ }^{17,18}$ Freqüências maiores, que variam de $0,8 \%$ a $25 \%$, têm sido relatadas nos casos em que a VCI do enxerto é implantada apenas no óstio das veias hepáticas média e esquerda do receptor (ME). ${ }^{11,13,14,17}$

Acredita-se que a maior freqüência de bloqueio de efluxo na reconstrução $\mathrm{ME}$ esteja relacionada a vários fatores. Apesar de estudos anatômicos demonstrarem que, no local da anastomose, a abertura formada pela secção do septo entre a VHM e a VHE tem diâmetro congruente com o da VCI do enxerto, ${ }^{19}$ esse óstio não corresponde ao menor calibre da via de efluxo. Em cerca de $85 \%$ dos indivíduos, ${ }^{19,20}$ a VHM e a VHE proximalmente à anastomose convergem, para formar um tronco único que, em sua desembocadura na VCI do receptor, possui um calibre menor que o da boca anastomótica, o que pode constituir um fator limitante para o fluxo. ${ }^{19}$ Mesmo nos casos em que o calibre não é limitante, pode ocorrer dificuldade de efluxo devido à torção da anastomose, causada pela diferença de orientação entre os vasos do receptor e do enxerto. ${ }^{16,19}$ Essa divergência de orientação acentua-se nos casos em que enxertos relativamente pequenos são implantados em lojas hepáticas amplas. ${ }^{21}$ Habitualmente, essa desproporção permite que o fígado deslize para o hipocôndrio direito, favorecendo sua oclusão posicional. ${ }^{1,17,21}$ Finalmente, a utilização do tronco único gera uma distância entre a boca anastomótica e a VCI, o que favorece adicionalmente a torção da anastomose..$^{16,22}$

A superioridade da reconstrução LL e da anastomose DME, referente à patência da via de efluxo do enxerto, não se repete quando é analisada a eficiência do retorno venoso durante a fase anepática do Tx. ${ }^{23} \mathrm{Na}$ reconstrução $\mathrm{ME}$, o pinçamento vascular é realizado na origem do tronco único, determinando uma constrição discreta da VCI. Já na reconstrução com as três veias hepáticas, o pinçamento da VCI é mais extenso. Esse posicionamento da pinça vascular determina queda de aproximadamente $23 \%$ do fluxo da VCI e de 12 a $15 \%$ do débito cardíaco, o que, embora não determine queda da pressão arterial, acarreta um aumento de $46 \%$ da pressão da VCI e redução da pressão de perfusão renal durante a fase anepática. ${ }^{24}$ Os efeitos hemodinâmicos são semelhantes na reconstrução LL, notando-se uma queda do débito cardíaco entre $19 \%$ e $25 \%$ e um aumento da resistência vascular periférica de aproximadamente $33 \%$ durante a fase anepática do Tx. ${ }^{23}$

A alternativa de reconstrução mais raramente empregada é a que utiliza o óstio formado pelas veias hepáticas direita e média (DM). ${ }^{6,9,15}$ Numa revisão recente realizada entre janeiro de 1998 e novembro de 2003 pelo mesmo grupo de pesquisa responsável pelo presente estudo de 170 pacientes submetidos a primeiro Tx com doador falecido, foram encontrados 54 casos operados por esse método. Nessa casuística, não foram diagnosticadas complicações da via de efluxo venoso do enxerto e a sobrevida atuarial dos pacientes, após um, três e cinco anos, foi de $94 \%, 91 \%$ e $91 \%$, respectivamente. No último ano analisado na casuística, $80 \%$ dos transplantes piggyback foram realizados por esse método. ${ }^{25}$

Esta técnica deve, teoricamente, limitar a constrição durante o pinçamento lateral da VCI, já que não necessita englobar o óstio da VHE como ocorre quando se utilizam as três veias hepáticas, além de manter um posicionamento favorável da anastomose por apresentar uma boca anastomótica em posição mais anterior. Entretanto, essas vantagens só se justificam se, de fato, a via de efluxo venoso obtida não apresentar restrições anatômicas tanto no sítio da anastomose como na desembocadura na VCI do receptor.

O objetivo do presente trabalho é comparar a congruência do perímetro da VCI com o perímetro das bocas anastomóticas e dos óstios de drenagem na VCI, obtidos por meio da utilização das modalidades DM e DME para reconstrução do efluxo venoso no Tx piggyback.

\section{MÉTODO}

Foram estudados prospectivamente 16 cadáveres frescos de ambos os sexos, cedidos pelo Serviço de Verificação de Óbitos da Capital (SVOC). O projeto foi aprovado pela Comissão de Ética para Análise de Projetos de Pesquisa do Hospital das Clínicas e da Faculdade de Medicina da Universidade de São Paulo (CAPPesq) e sua realização foi feita mediante anuência por escrito do SVOC.

Os critérios para inclusão de cada cadáver na pesquisa foram: idade igual ou superior a 18 anos; ausência de antecedente de procedimentos cirúrgicos hepáticos ou sobre a confluência hepato-caval; ausência de antecedente de trombose das veias hepáticas ou da VCI; ausência de antecedente ou achado, após a abertura da cavidade, de cirrose hepática; e ausência de variações anatômicas na confluência hepatocaval que impedissem as medidas pretendidas. 
De cada cadáver incluído no estudo, foram registrados os seguintes dados: nome completo, número de registro no SVOC, sexo, idade, altura e peso estimados, causa do óbito, antecedentes mórbidos e cirúrgicos conhecidos, além da data do óbito e do estudo post mortem.

O procedimento operatório foi padronizado em todos os casos. Inicialmente, foi realizada incisão mediana desde o manúbrio até a sínfise púbica. Em seguida, a parede torácica anterior foi retirada por meio de incisão dos arcos costais em sua parte cartilaginosa bilateralmente, conseguindo-se, assim, amplo acesso aos órgãos intratorácicos e intra-abdominais. Os passos subseqüentes da dissecção obedeceram a seguinte rotina: 1- Abertura do saco pericárdico, isolamento e pinçamento da porção supradiafragmática da VCI; 2- Dissecção e pinçamento da porção infra-hepática da VCI acima das veias renais; 3- Dissecção hepática seccionando-se os ligamentos coronários e triangulares bilateralmente; 4 - Isolamento e ligadura dos elementos do hilo hepático; 5 - Isolamento do lobo caudado do fígado da porção retro-hepática da VCI por meio da ligadura dos vasos provenientes do parênquima hepático; 6 Identificação e secção da VHD, VHM e VHE junto ao fígado ou na espessura do parênquima hepático, de modo a preservar pelo menos $5 \mathrm{~mm}$ de extensão da VHD junto à sua desembocadura na VCI e $5 \mathrm{~mm}$ das VHE e VHM distais à sua confluência no tronco único; 7 - Término da hepatectomia com remoção do fígado, permitindo a exposição da VCI desde a cúpula hemidiafragmática direita até a confluência das veias renais.

\section{Estudo Morfométrico}

Após a exposição completa da VCI e veias hepáticas, foi realizado o estudo morfométrico da confluência hepato-caval, analisando-se as variáveis abaixo:

- perímetro dos óstios utilizados nas reconstruções DM (PDM) e DME (PDME);

- perímetro dos óstios de desembocadura na VCI das reconstruções DM (PoDM) e DME (PoDME);

- perímetro da VCI no ponto de passagem pelo seu forame no diafragma (PVCI).

Inicialmente, foram aplicados fios de tração (nylon ou polipropileno) nos quatro pontos cardinais da boca de cada tipo de reconstrução empregada. Para padronização da intensidade da tração, a extremidade livre de cada fio foi conectada a um peso de valor idêntico e conhecido (100 g).

Os fios foram apoiados em um suporte metálico especial em forma de funil, composto por dois círculos concêntricos dispostos em planos distintos e paralelos (Figura 1A e 1B). O círculo de menor diâmetro $(67 \mathrm{~mm})$ foi posicionado no plano coronal do perímetro vascular estudado, sendo utilizado para orientar a direção da tração exercida sobre o vaso (Figura 1C). O círculo de maior diâmetro $(185 \mathrm{~mm})$ foi utilizado para manter os pesos de tração sob a ação da força da gravidade. Assim, procurou-se exercer um vetor de força constante na parede do vaso, contraposto por outro vetor de mesma intensidade, porém de sentido contrário. Desse modo, a tração aplicada nos vasos foi semelhante e uniforme em todos os casos. Com a retificação dos quatro segmentos de sua parede definidos pelos pontos de tração, o vaso assumiu um formato aproximadamente quadrangular, o que facilitou a aferição ulterior do perímetro (Figura 1C).

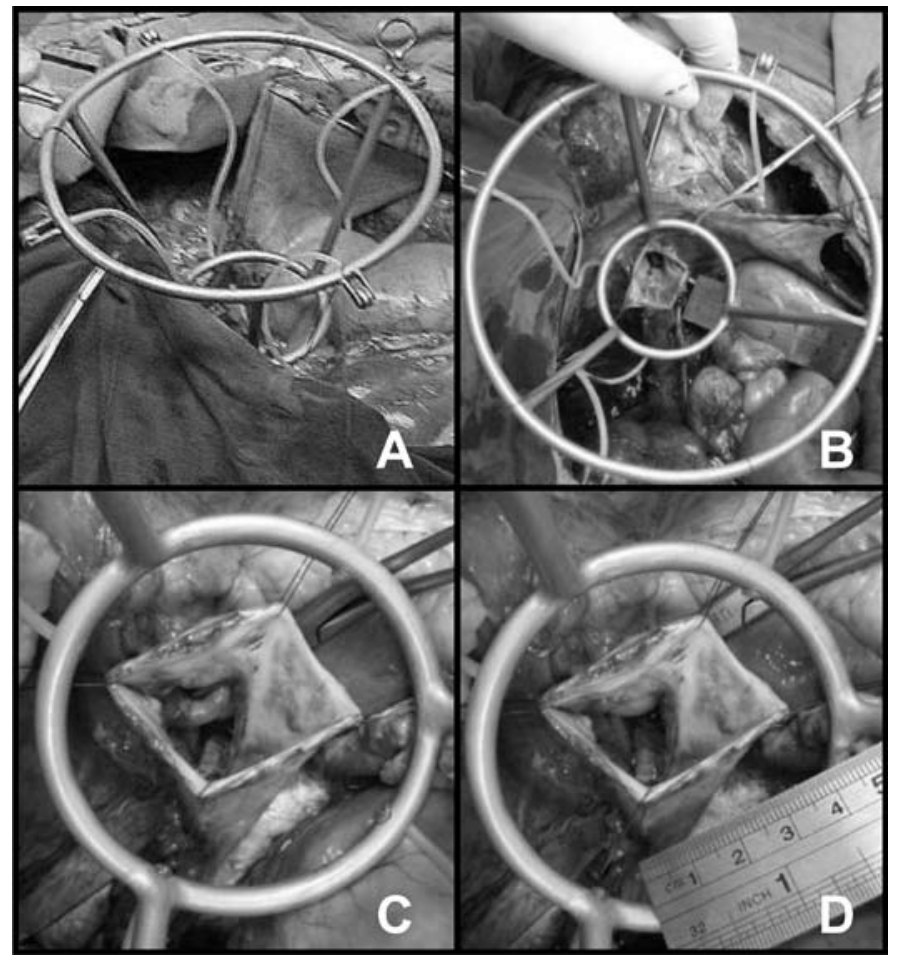

Figura 1: Estudo morfométrico. A e B-Suporte metálico especial, em forma de funil, composto por dois círculos concêntricos dispostos em planos distintos e paralelos; C- O círculo de menor diâmetro foi mantido no nível do perímetro vascular estudado e utilizado para orientar no plano coronal a direção da tração exercida sobre o vaso. Com a retificação dos quatro segmentos de sua parede definidos pelos pontos de tração, o vaso assumiu um formato aproximadamente quadrangular, o que facilitou a aferição ulterior do perímetro; D- No momento de obtenção das imagens, uma régua metálica milimetrada foi posicionada no mesmo plano do perímetro vascular estudado.

A medida do perímetro dos óstios de anastomose e desembocadura foi iniciada, em todos os casos, pela modalidade DM, seccionando-se a porção da parede anterior da VCI interposta entre os óstios da VHD e da VHM. Inicialmente, foi realizada a medida do PDM e do PoDM. A seguir, o septo existente entre as VHM e VHE foi seccionado para a realização da medida do PDME e do PoDME. Por fim, o PVCI foi aferido no local de passagem do vaso pelo diafragma, após o descolamento e isolamento da VCI de seu forame.

Foram obtidas imagens digitalizadas de todos os perímetros de interesse por meio de uma câmera digital (Canon Power Shot A85, Canon Marketing Sdn. Bhd., Shah Alam, Selangor, Malásia). No momento da obtenção dessas imagens, uma régua metálica milimetrada foi posicionada no mesmo plano do perímetro vascular estudado, de forma a ser registrada nas fotografias (Figura 1D).

Ulteriormente, as imagens da régua milimetrada foram manipuladas digitalmente por meio do programa Corel Photo-Paint 7.0 (Corel Corporation, Ottawa, Ontário, Canadá), obtendo-se uma "figura de calibração" quadrada de $10 \mathrm{~mm}$ de lado, sobreposta no quadrante superior esquerdo da foto original (Figura 2A e 2B).

A análise morfométrica foi realizada por meio do Sistema Analisador de Imagens KS300, versão 3.0 (Carl Zeiss Vision GmbH, Hallbergmoos, Alemanha), acoplado a um microcomputador. 


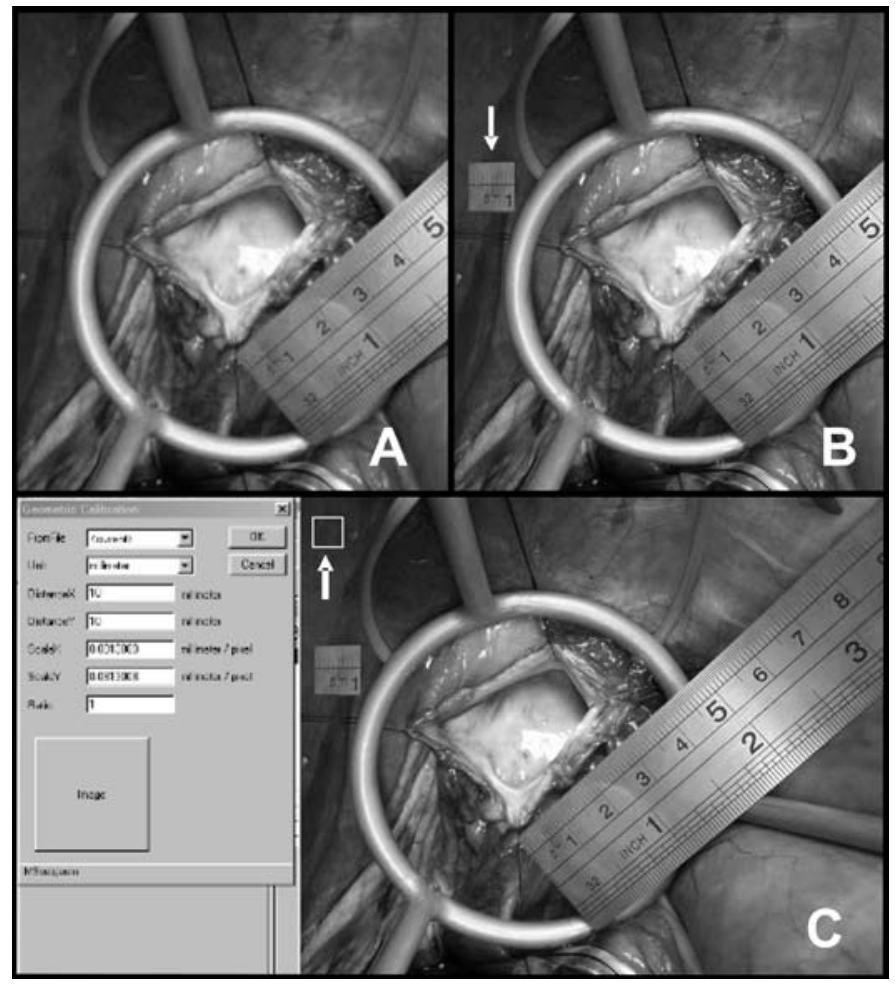

Figura 2: Estudo morfométrico. A- Imagem digitalizada original; BManipulação digital da imagem da régua milimetrada com criação de uma "figura de calibração" quadrada, com face de $10 \mathrm{~mm}$, que foi sobreposta no quadrante superior esquerdo da fotografia original (seta); C- Fotografia da tela de calibração geométrica do programa analisador de imagens KS300. Observe a colocação de "milímetros" como unidade de medida desejada e as medidas da "figura de calibração" (10 x 10 mm) nas distâncias dos eixos " $X$ " e "Y". Após o ajuste das medidas na tela o programa KS300 oferece um "molde" geométrico para calibração da imagem (seta).

Para a correção da ampliação das imagens e para obtenção de dados em escala decimal, realizou-se a calibração da imagem por meio da "figura de calibração" de 10 x $10 \mathrm{~mm}$ incluída digitalmente nas fotos (Figura 2C). Para tanto, utilizou-se a janela "Geometric Calibration" do programa, selecionando-se a unidade de medida desejada (milímetros).

A partir disso, o programa KS300 oferece um "molde" geométrico, que quando sobreposto e ajustado às dimensões da "figura de calibração" permitiu a conversão da unidade de medida de pixels para milímetros (Figura 2C e 3A).

Após calibração da imagem, utilizou-se o recurso gráfico do programa para demarcar as estruturas a serem quantificadas (Figura 3B). Com o auxílio do mouse, foram delineados e medidos automaticamente, a partir da escala criada, os perímetros de interesse (Figura 3C). Realizaram-se três medidas consecutivas de cada perímetro estudado, utilizando-se para análise a média aritmética desses valores.

\section{Análise Estatística}

As distribuições dos perímetros foram analisadas em relação à normalidade e esfericidade pelos Testes de Shapiro-Wilk e Mauchly, respectivamente. Os perímetros estudados foram comparados por

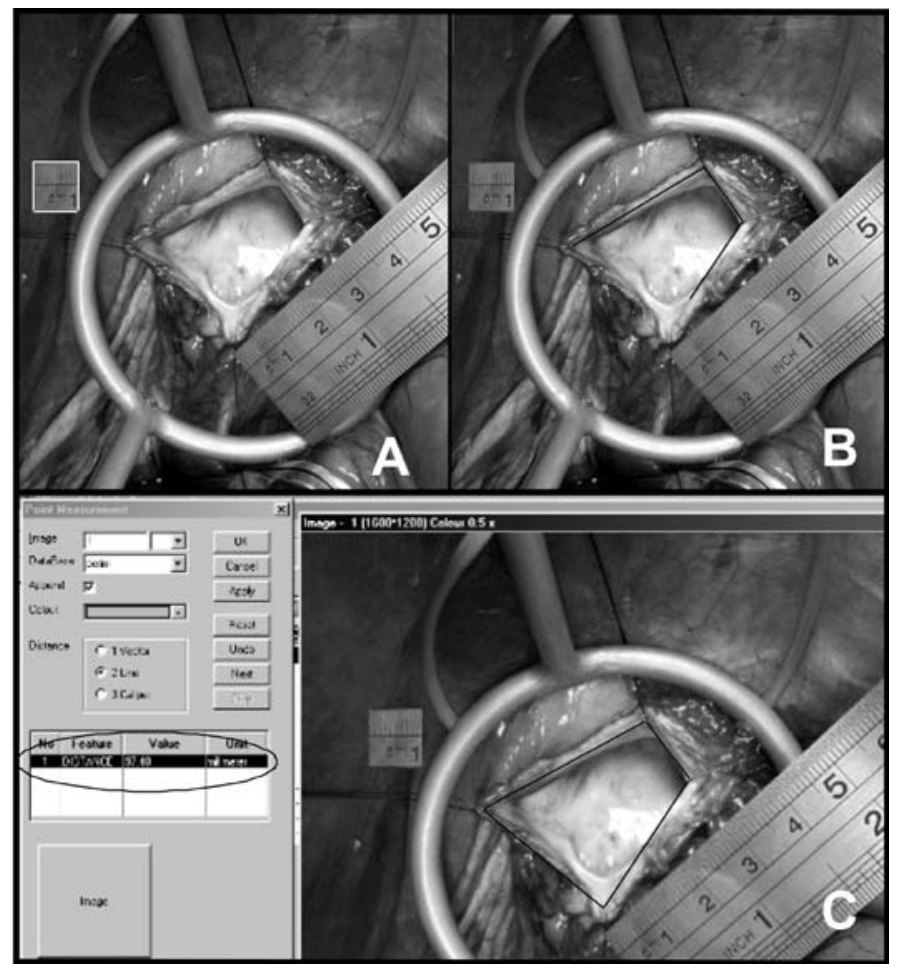

Figura 3: Estudo morfométrico. A- Ajuste e sobreposição do "molde" geométrico do programa à "figura de calibração", permitindo o cálculo de um "fator de calibração"; B- Demarcação parcial do perímetro vascular estudado: C-Demarcação total do perímetro vascular com resultado automático em milímetros (em destaque).

meio de análise de variância (ANOVA) para medidas repetidas e pelo Teste de Bonferroni para comparações múltiplas. Utilizou-se um nível de significância de $5 \%(\alpha=0,05)$. As análises foram realizadas por meio do programa SPSS for Windows versão 9.0 (Statistical Package for the Social Sciences Inc., Chicago, IL, EUA).

O tamanho da amostra foi estimado por meio do programa Sample Power versão 1.0 (Statistical Package for the Social Sciences Inc., Chicago, IL, EUA), fixando-se os erros de tipo I e II em $5 \%$ e $20 \%$, respectivamente, procurando-se detectar uma diferença de $1,5 \mathrm{~mm}$ entre o diâmetro da VCI e o diâmetro dos óstios das vias de efluxo venoso analisadas, e considerando-se o diâmetro médio da VCI como $24,4 \pm 2,0 \mathrm{~mm}^{19}$

\section{RESULTADO}

Foram estudados 11 casos do sexo masculino (68,8\%). A média de idade foi de $63,7 \pm 15,7$ anos (40 a 83 anos). Nenhum dos casos avaliados enquadrou-se nos critérios de exclusão, sendo todos, dessa forma, incluídos na casuística. Três cadáveres apresentavam antecedente de etilismo crônico sem evidência macroscópica, no entanto, de cirrose hepática.

Os valores individuais dos perímetros analisados são apresentados na Tabela 1. Foram obtidos dados completos para todas as variáveis, exceto para PoDME. Nessa variável, não foi possível identificar com precisão o óstio de desembocadura na VCI em sete casos $(43,8 \%)$, optando-se pela exclusão desse perímetro das análises ulteriores. 
A distribuição dos valores dos perímetros estudados é apresentada na Figura 4, por meio de gráfico de box-plot.

A distribuição dos perímetros estudados obedeceu às suposições de normalidade (Tabela 1) e esfericidade $(\mathrm{p}=0,062)$. Na análise de variância (ANOVA) para medidas repetidas, encontrou-se uma diferença estatisticamente significante entre os perímetros estudados $(\mathrm{p}<0,001)$. O teste para comparações múltiplas de Bonferroni demonstrou: um valor médio significantemente maior de todos os perímetros em relação ao da VCI; ausência de diferença estatisticamente significante entre o PDM e PoDM; além de um valor médio significantemente menor desses dois perímetros em relação ao PDME (Tabela 2).

\section{DISCUSSÃO}

A preservação da VCI no Tx foi descrita inicialmente por Calne e Williams em 1968. ${ }^{26}$ Nessa ocasião, os autores se depararam com um

Tabela 1: Resultados.

\begin{tabular}{|c|c|c|c|c|c|}
\hline Caso no & $\begin{array}{l}\text { PVCI } \\
(\mathrm{mm})\end{array}$ & $\begin{array}{l}\text { PDM } \\
(\mathrm{mm})\end{array}$ & $\begin{array}{l}\text { PoDM } \\
(\mathrm{mm})\end{array}$ & $\begin{array}{c}\text { PDME } \\
(\mathrm{mm})\end{array}$ & $\begin{array}{c}\text { PoDME } \\
\text { (mm) }\end{array}$ \\
\hline 1 & 115,1 & 105,4 & 99,4 & 146,4 & - \\
\hline 2 & 102,3 & 147,2 & 125,7 & 171,4 & 149,7 \\
\hline 3 & 112,7 & 141,6 & 142,5 & 152,7 & - \\
\hline 4 & 121,7 & 130,8 & 130,8 & 141,9 & 120,7 \\
\hline 5 & 90,2 & 103,5 & 101,1 & 124,0 & 104,6 \\
\hline 6 & 114,9 & 135,3 & 124,0 & 136,7 & - \\
\hline 7 & 98,2 & 108,2 & 106,5 & 137,1 & 121,4 \\
\hline 8 & 119,2 & 129,9 & 127,5 & 154,2 & - \\
\hline 9 & 129,9 & 134,5 & 132,5 & 135,9 & - \\
\hline 10 & 117,4 & 157,0 & 124,1 & 171,0 & 136,4 \\
\hline 11 & 117,0 & 133,0 & 125,1 & 155,7 & 152,5 \\
\hline 12 & 76,8 & 92,8 & 85,6 & 90,3 & - \\
\hline 13 & 113,1 & 123,8 & 110,8 & 120,2 & - \\
\hline 14 & 67,1 & 85,7 & 84,3 & 83,5 & 83,5 \\
\hline 15 & 137,5 & 132,8 & 136,2 & 141,1 & 135,3 \\
\hline 16 & 93,4 & 109,2 & 109,9 & 132,9 & 112,6 \\
\hline média \pm dp & $107,9 \pm 18,8$ & $123,2 \pm 20,1$ & $116,6 \pm 17,5$ & $137,2 \pm 24,3$ & - \\
\hline mediana & 114,0 & 130,4 & 124,0 & 139,1 & - \\
\hline normalidade* & 0,387 & 0,522 & 0,348 & 0,174 & - \\
\hline
\end{tabular}

dp-desvio padrão, PDM-perímetro da modalidade DM, PDME-perímetro da modalidade DME. PoDM-perímetro do óstio de desembocadura na veia cava inferior da modalidade DM, PoDME- perímetro do óstio de desembocadura na veia cava inferior da modalidade DME *Nível descritivo (p) pelo Teste de Shapiro-Wilk
Tabela 2: Comparações múltiplas.

\begin{tabular}{|c|c|c|c|c|c|}
\hline \multirow{2}{*}{ Comparações } & \multirow{2}{*}{$\begin{array}{l}\text { Diferença } \\
\text { média }\end{array}$} & \multirow{2}{*}{ p } & \multirow{2}{*}{$\mathbf{p}^{\mathrm{a}}$} & \multicolumn{2}{|c|}{$\begin{array}{c}\text { Intervalo de } \\
\text { confiança } 95 \% \text { a }\end{array}$} \\
\hline & & & & $\begin{array}{l}\text { Limite } \\
\text { inferior }\end{array}$ & $\begin{array}{l}\text { Limite } \\
\text { superior }\end{array}$ \\
\hline PVCI vs. PDM & $-15,3^{*}$ & 0,001 & 0,003 & $-25,9$ & $-4,6$ \\
\hline PVCI vs. PoDM & $-8,7^{*}$ & 0,005 & 0,027 & $-16,7$ & $-0,8$ \\
\hline PVCI vs. PDME & $-29,3^{*}$ & 0,000 & 0,000 & $-43,0$ & $-15,6$ \\
\hline PDM vs. PoDM & 6,5 & 0,014 & 0,086 & $-0,6$ & 13,7 \\
\hline PDM vs. PDME & $-14,0^{*}$ & 0,001 & 0,004 & $-24,0$ & $-4,1$ \\
\hline PoDM vs. PDME & $-20,5^{\star}$ & 0,000 & 0,001 & $-32,8$ & $-8,3$ \\
\hline
\end{tabular}

PDM-perímetro da modalidade DM, PDME-perímetro da modalidade $D M E, P O D M$ - perímetro do óstio de desembocadura na veia cava inferior da modalidade DM, PVCl-perímetro da VCl

* diferença média significante no nível $\alpha=0,05$

a ajustado para comparações múltiplas pelo método de Bonferroni

Figura 4: Distribuição dos valores dos perímetros da VCl e das modalidades de reconstrução DME (PDME) e DM (PDM e PoDM). São representados a mediana, os quartis 25 e $75 \%$ e os valores mínimo e máximo encontrados.

O - Outliers

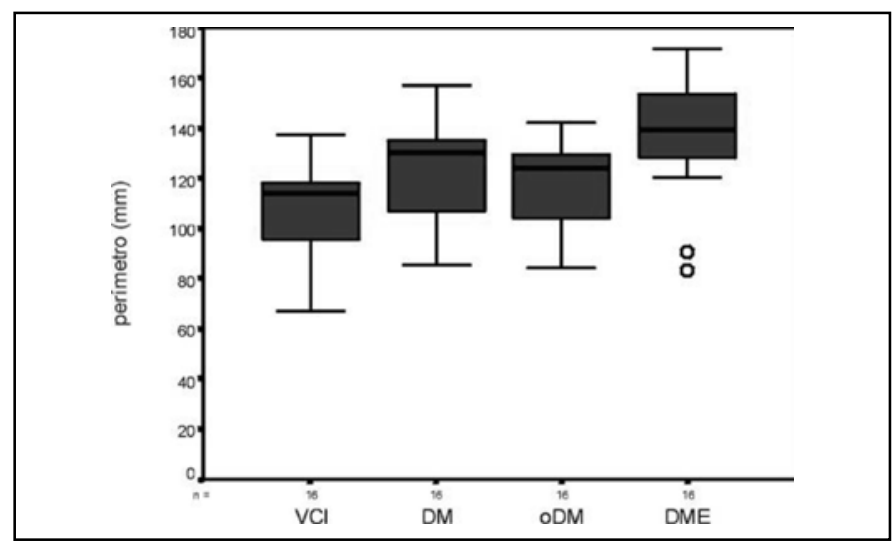

paciente adulto que recebia um fígado proveniente de uma criança, determinando uma grande desproporção entre os perímetros da VCI do enxerto e do receptor. Para contornar essa situação optaram, então, pela liberação do fígado nativo da VCI do receptor, a qual foi preservada. A reconstrução do efluxo venoso foi realizada pela implantação da porção supra-hepática da VCI do enxerto na boca formada pela VHM e VHE do receptor. ${ }^{26}$

A preservação da VCI foi popularizada posteriormente, recebendo a denominação "piggyback" por Tzakis et al $\mathrm{O}$ método ganhou ampla aceitação por seu perfil hemodinâmico mais favorável na fase anepática, quando comparado ao Tx convencional, ${ }^{17,18} \mathrm{e}$ pelas vantagens adicionais relatadas, como diminuição do tempo de isquemia quente, diminuição do sangramento e transfusão perioperatória e menor incidência de insuficiência renal pósoperatória. ${ }^{27}$ Atualmente, constitui a técnica preferida na maioria 
dos centros mundiais, sendo aplicada em mais de $90 \%$ dos casos quando se objetiva evitar os inconvenientes da ressecção da VCI do receptor. ${ }^{27}$ Apesar dessas vantagens, o Tx piggyback apresenta diversos relatos de maior incidência de complicações da drenagem venosa do enxerto. ${ }^{7,10,12,28}$

A restauração da continuidade hepato-caval é um passo essencial no Tx piggyback, pois, diferentemente do Tx convencional em que a via de efluxo é sintópica e mantém um diâmetro mínimo igual ao da VCI naquele, a via de efluxo pode, na dependência de fatores anatômicos relacionados com o tipo de reconstrução empregado, impor maior resistência ao fluxo. ${ }^{2,21,22}$

A reconstrução do efluxo venoso no Tx piggyback pode dar-se por diversas alternativas de anastomose entre a porção cranial da VCI do enxerto e a VCI do receptor: utilizando as diferentes combinações dos óstios das veias hepáticas do receptor ou por meio de uma anastomose cavo-caval LL. ${ }^{3,6,9,13,22,25,29}$ A freqüência de bloqueio do efluxo e as alterações hemodinâmicas durante a fase anepática do Tx, por sua vez, estão relacionadas a fatores anatômicos do tipo de reconstrução empregado. ${ }^{1,16}$

Os fatores anatômicos mais importantes que devem ser avaliados na escolha entre as diferentes modalidades de reconstrução do efluxo venoso do enxerto são: orientação do eixo da anastomose em relação ao da VCI; tamanho do enxerto em relação à loja hepática do receptor, o que pode favorecer a oclusão posicional do enxerto, além do tamanho e congruência entre as bocas anastomóticas da VCI do enxerto e do receptor. ${ }^{30,31}$

Por sua situação anatômica, uma das primeiras variantes utilizadas no Tx piggyback foi a ME. Wind et a ${ }^{19}$ avaliaram a exeqüibilidade desse tipo de modalidade de reconstrução do efluxo venoso. Nesse trabalho, a secção do septo entre as VHM e VHE criou um óstio de $23,8 \pm 2,3 \mathrm{~mm}$, o qual se revelou compatível com o diâmetro da VCI $(24,4 \pm 2,0 \mathrm{~mm})$. No entanto, foi encontrado um óstio de desembocadura do tronco comum na VCI de apenas 13,6 $\pm 1,9 \mathrm{~mm}$, o que equivale a aproximadamente $50 \%$ do diâmetro da VCI. Esse valor reflete achados de outros autores ${ }^{32,33}$ e constitui fator limitante ao fluxo venoso nesse tipo de reconstrução.

O fluxo é uma grandeza biofísica expressa em termos de volume por unidade de tempo. ${ }^{34}$ Essa relação pode ser expressa pela equação: Fluxo $=$ velocidade $\mathrm{x}$ área. A resistência hidrodinâmica ao fluxo, por sua vez, depende do comprimento e raio do vaso, além da viscosidade do sangue ${ }^{34}$ Essas relações são mostradas para o cálculo da resistência vascular pela Lei de Poiseuille:

$$
\text { RESISTÊNCIA }=\frac{8 \cdot \eta \cdot C}{\pi \cdot(r)^{4}}
$$

Onde:

$\pi=3,1416$

$\mathrm{C}=$ comprimento do vaso

$\eta=$ viscosidade do sangue

$\mathrm{r}=$ raio do vaso

A maior influência na determinação da resistência é dada pelo raio do vaso. Por essa razão, mesmo pequenas variações no calibre do vaso determinam grandes aumentos na resistência vascular. Utilizando os dados do estudo de Wind et a ${ }^{19}$ para a modalidade ME, podemos obter que a resistência ao fluxo no óstio de desembocadura da ME é aproximadamente 10,42 vezes ou $1.042 \%$ maior do que a da VCI.

Admitindo-se que na condição do Tx o fluxo tende a se manter constante apesar da estenose e que não existe circulação colateral, espera-se que ocorra um aumento da pressão nesse segmento de vaso na mesma proporção do aumento da resistência ( $\Delta$ Pressão $=$ Fluxo x Resistência).

Na prática, esse aumento da pressão venosa é a variável utilizada na maioria dos trabalhos que avaliam complicações do efluxo venoso hepático no Tx. Habitualmente, gradientes de até $3 \mathrm{~mm} \mathrm{Hg}$ são considerados discretos. ${ }^{13,28}$ Entretanto, outros autores relatam gradiente médio de 5,6 $\mathrm{mm} \mathrm{Hg} \mathrm{em} \mathrm{pacientes} \mathrm{sem} \mathrm{sinais} \mathrm{clínicos} \mathrm{de}$ bloqueio de efluxo após Tx. ${ }^{13}$

Não foram encontrados estudos que avaliassem detalhadamente os aspectos anatômicos envolvidos nas demais modalidades de reconstrução do efluxo venoso. A modalidade DME é amplamente utilizada, e tem como vantagem oferecer uma boca anastomótica ampla e, assim, teoricamente, menos sujeita a complicações do bloqueio do efluxo venoso. ${ }^{1,24,30}$ A utilização da modalidade DM, por sua vez, é pouco referida na literatura. ${ }^{9,25}$ Essa técnica, teoricamente, pode reunir todas as vantagens dos outros métodos: limitar a constrição durante o pinçamento lateral da VCI, já que não necessita englobar o óstio da VHE, como ocorre quando se utiliza as três veias hepáticas; manter um posicionamento favorável da anastomose por apresentar uma boca anastomótica numa posição mais anterior e obter uma via de efluxo sem restrições em relação ao calibre da VCI do enxerto, tanto no sítio da anastomose como na desembocadura na VCI do receptor.

Diferentemente de outros estudos anatômicos, optou-se, no presente trabalho, por medir os perímetros ao invés dos diâmetros vasculares. Por possuírem menor quantidade de fibras musculares e elásticas, as veias no cadáver têm uma conformação predominantemente elíptica, diversamente das artérias que tendem a manter sua forma original circular. ${ }^{35} \mathrm{Na}$ maioria dos casos, a secção transversal da VCI determina uma figura elíptica e não circular, com diâmetro anteroposterior menor que o transversal. Assim, diversos autores, utilizando metodologias variadas, encontraram resultados discrepantes em relação ao diâmetro da VCI.

Os valores médios encontrados por Camargo et ${ }^{\beta 3}{ }^{\beta 3}$ para os diâmetros antero-posterior e transversal foram $16 \mathrm{~mm}$ e $55 \mathrm{~mm}$, utilizando peças fixadas em formalina. Esse resultado é próximo ao reportado por Chang $e a^{32}$ que encontraram $18 \mathrm{~mm}$ em média para o diâmetro antero-posterior. Por outro lado, Nakamura et $a l^{20}$ encontraram um diâmetro médio da VCI de $34 \pm 5 \mathrm{~mm}$ (variando de 25 a $45 \mathrm{~mm}$ ), no nível do seu forame no diafragma, enquanto Wind et a $l^{19}$ encontraram um valor de 24,4 $\pm 2,0 \mathrm{~mm}$. Essa disparidade de resultados pode ser explicada pela diferença e heterogeneidade dos métodos de medida e fixação empregados por cada autor.

No presente estudo, acredita-se que o cuidado metodológico de realizar a aferição dos perímetros em cadáveres frescos com aplicação de uma tração conhecida e constante nas estruturas vasculares possa ter permitido a obtenção de medidas mais fidedignas e de maior reprodutibilidade. A utilização de peças fixadas tem a desvantagem de gerar deformações inerentes ao processo de fixação, visto que, neste momento, os vasos, principalmente as veias, não estão sujeitos às suas condições fisiológicas. A medida do diâmetro vascular por meio de velas metálicas, como foi feito por Wind et $a l,{ }^{19}$ tem 
a desvantagem de não controlar a intensidade da força despendida pelo examinador para a introdução do instrumento na luz dos vasos, além de haver dificuldades técnicas para realizar medidas de orifícios dispostos em planos distintos mas próximos.

O perímetro também parece ser mais útil para a avaliação da adequação técnica de uma anastomose, pois fornece uma medida da congruência, sendo, assim, de maior interesse prático para a confecção da sutura cirúrgica entre as estruturas. Na interpretação dos resultados do presente estudo, a VCI foi utilizada como controle para as comparações realizadas, já que no Tx é a via condutora final do retorno venoso do enxerto.

Com o intuito de facilitar e padronizar a realização da medida dos perímetros da VCI e das bocas anastomóticas, bem como dos óstios de desembocadura das modalidades de reconstrução estudadas, um suporte metálico foi idealizado especialmente para o projeto. Esse suporte foi desenhado em forma de funil, composto por dois círculos concêntricos dispostos em planos distintos e paralelos. Com esta disposição, o círculo de menor diâmetro foi utilizado para orientar, no plano coronal, a direção e o ângulo de tração exercida sobre o vaso. O círculo de maior diâmetro foi utilizado para manter os pesos de tração sob a ação exclusiva da força de gravidade.

A escolha de um programa analisador de imagens das medidas realizadas visou à obtenção de medidas com maior precisão, eliminando a inconstância da aferição com instrumentos manuais e permitindo uma padronização metodológica com menor viés. O Sistema Analisador de Imagens KS300 é utilizado rotineiramente acoplado a um microscópio de luz, para avaliações histomorfométricas. Nessa situação, o programa permite calibração e correção automáticas das medidas realizadas dos aumentos convencionais dos microscópios. Sua utilização para imagens macroscópicas dependeu da criação de uma metodologia específica, com a aquisição, na imagem digitalizada, de uma escala ("figura de calibração"), o que permitiu determinar e corrigir a ampliação das imagens e obter a medida dos perímetros vasculares em unidade métricas convencionais.

Nas duas modalidades estudadas, a VCI apresentou um perímetro médio $(107,9 \pm 18,8 \mathrm{~mm})$ sempre menor que o das vias de efluxo. Em média, o PME foi 29,3 $\pm 18,0 \mathrm{~mm}$ maior que o PVCI ( $p<0,001)$. Se, por um lado, esse achado significa uma via de efluxo sem restrições anatômicas, por outro, indica uma desproporção de bocas que pode dificultar tecnicamente a confecção da anastomose.

Aucejo $e{ }^{3} l^{30}$ relatam a ocorrência de obstrução isolada da VHD em casos submetidos a Tx piggyback pela modalidade DME. Analisando os fatores implicados na ocorrência desse fenômeno, os autores valorizam o inconveniente da desproporção entre a boca anastomótica do receptor (mais ampla no sentido látero-lateral) e a porção supra-hepática da VCI do enxerto. Argumentam que, após a realização da anastomose, a VCI do enxerto sofre uma tração mais intensa no sentido transversal, o que reduz o seu diâmetro antero-posterior. Com isso, a boca anastomótica torna-se "ovalada", deformidade que diminui sua área de secção transversal quando comparada a uma anastomose de forma aproximadamente circular. Por essa razão, os autores sugerem que uma maior congruência entre as bocas anastomóticas pode ter impacto favorável na freqüência de bloqueio da via de efluxo venoso do enxerto.

Quando analisamos a modalidade DM, encontramos que o PDM foi em média 15,3 \pm 14,0 $\mathrm{mm}$ maior do que o PVCI. Da mesma forma, o PoDM foi $8,7 \pm 10,5 \mathrm{~mm}$ maior que o PVCI. Assim, não foram encontrados indícios de que a modalidade DM possa apresentar inconvenientes anatômicos ao efluxo venoso do enxerto, tanto no nível da anastomose como no óstio de desembocadura na VCI. Ao mesmo tempo, existe melhor congruência entre as bocas anastomóticas quando comparada com a modalidade DME.

Quando analisamos cada caso isoladamente, surgem diferenças entre as duas modalidades de reconstrução do efluxo venoso no Tx piggyback.

Em todos os casos o PDME foi maior que o PVCI. Já na modalidade DM, o PVCI foi maior que o PDM, ou o PoDM nos casos 1, 13 e 15. Nesses três casos (18.8\%), a diferença entre o PVCI e o menor perímetro da via de efluxo foi de $15,7 \mathrm{~mm}, 2,3 \mathrm{~mm}$ e $3,7 \mathrm{~mm}$, respectivamente.

Conhecendo-se o perímetro e partindo-se da premissa que, sob condições fisiológicas as veias assumem uma forma aproximadamente circular, ${ }^{33}$ é possível aplicar a Lei de Poiseuille e inferir que na situação de maior desproporção (caso 1) há no óstio de desembocadura da DM um incremento na resistência vascular de aproximadamente $83 \%$ ou 1,83 vezes em relação à VCI. Considerando-se um fluxo constante, podemos prever um aumento proporcional da pressão venosa, ou seja, um gradiente de pressão que sob condições fisiológicas (sem constrição) fosse de $2 \mathrm{~mm} \mathrm{Hg}$, e apresentaria um aumento para 3,7 $\mathrm{mm} \mathrm{Hg}$. Utilizando o mesmo raciocínio, o gradiente de pressão esperado, utilizando as constrições dos casos 13 e 15, seria de apenas 2,1 $\mathrm{mm} \mathrm{Hg}$ e 2,3 $\mathrm{mm} \mathrm{Hg}$, respectivamente.

Com esse raciocínio teórico, temos que, em apenas um caso $(6,3 \%)$, a via de efluxo criada pela modalidade DM causaria uma redução de calibre suficiente para provocar aumento do gradiente de pressão acima dos limites fisiológicos ( $3 \mathrm{~mm} \mathrm{Hg}$ ), mas ainda abaixo do limite clinicamente relevante $(5,6 \mathrm{~mm} \mathrm{Hg}) .{ }^{19}$

\section{CONCLUSÃO}

A partir dos resultados obtidos, podemos concluir que a via de efluxo venoso obtida na modalidade DM de Tx piggyback apresenta perímetro maior que o da VCI, tanto no ponto de anastomose quanto no óstio de desembocadura na VCI, não determinando restrições anatômicas para a drenagem venosa do enxerto hepático. Além disso, em comparação com a modalidade DME, a modalidade DM apresenta perímetro mais congruente com o da VCI.

\section{ABSTRACT}

Introduction: The incidence of hepatic venous outflow complications after piggyback liver transplantation varies according to the type of venous reconstruction. The use of the three main hepatic veins of the recipient (RML) has lower frequency of hepatic venous outflow obstruction. On the other hand, the venous return during the anhepatic phase was reduced. The use of the right and middle hepatic veins (RM) limits the inferior vena cava (IVC) constriction. However, this benefit is only justified if a hepatic venous tract with no anatomical restrictions can be obtained. Purpose: To compare the congruence of the IVC perimeter with the perimeter of the venous outflow tract at 
the anastomotic site and its opening into the IVC both in the RM and RML modalities. Methods: A prospective morphometric study was performed in 16 fresh human cadavers by measuring the perimeter of the IVC (IVCP) and, in RM and RML reconstructions, the perimeter of the venous outflow tract at the anastomotic site (RMP and RMLP) and at its opening into the IVC (RMoP and RMLoP). The statistical analysis was performed using the variance analysis (ANOVA) for repeated measurements. Results: The mean RMLP (137.2 $\pm 24.3 \mathrm{~mm}$; $\mathrm{p}<0.001), \operatorname{RMP}(123.2 \pm 20.1 \mathrm{~mm} ; \mathrm{p}=0.003)$ and RMoP $(116.6 \pm 17.5 \mathrm{~mm} ; \mathrm{p}=0.027)$ amounts were significantly larger than IVCP $(107.9 \pm$ $18.8 \mathrm{~mm})$. RMLP amounts were significantly larger than $\operatorname{RMP}(\mathrm{p}=0.004)$ and $\mathrm{RMoP}(\mathrm{p}=0.001)$. Conclusion: $\mathrm{RM}$ reconstruction presents a larger perimeter than IVC both at the anastomotic site and at the opening into IVC. When comparing to RML, the RM modality presents a more congruent perimeter with IVC.

Keywords: Anatomy, Hepatic Veins, Liver Circulation, Comparative Study, Cadaver.

\section{REFERÊNCIAS}

1. Navarro F, Moine MCL, Fabre JM, Belghiti J, Cherqui D, René A, et al. Specific complications of orthotopic liver transplantation with preservation of retrohepatic vena cava: review of 1361 cases. Transplantation. 1999;68(5):646-50.

2. Shaw BW Jr, Martin DJ, Marquez JM, Kang YG, Bugbee AC Jr, Iwatsuki S, at al. Venous bypass clinical liver transplantation. Ann Surg. 1984;200(4):524-34.

3. Belghiti J, Panis Y, Sauvanet A, Gayet B, Fekete F. A new technique of side to side caval anastomosis during orthotopic hepatic transplantation without inferior vena caval occlusion. Surg Gynecol Obstet. 1992;175(5):270-2.

4. Acosta F, Sansano T, Robles R, Contreras RF, Reche M, Beltran R, et al. Hemodynamic consequences of portal and lateral clamping of the inferior vena cava during liver transplantation. Transplant Proc. 1999;31(6):2413-4.

5. Starzl TE, Marchioro TL, Von Kaulla KN, Hermann G, Brittain RS, Waddell WR. Homotransplantation of the liver in humans. Surg Gynecol Obstet. 1963;117(6): 659-75.

6. Isern MR, Massarollo PC, de Carvalho EM, Baia CE, Kavakama J, de Andrade Lima $\mathrm{P}$, et al. Randomized trial comparing pulmonary alterations after conventional with venovenous bypass versus piggyback liver transplantation. Liver Transpl. 2004;10(3):425-33.

7. Orons PD, Hari AK, Zajko AB, Marsh JW. Thrombolysis and endovascular stent for inferior vena caval thrombosis in a liver transplant recipient. Transplantation. 1997;64(9): 1357-61.

8. Lauchart W, Koveker G, Viebahn R, Schott U, Judt-Stelzer G. No impairment of hepatic venous outflow after "piggy-back" liver transplantation. Transplant Proc. 1997;29(7):2864-5

9. Tzakis A, Todo S, Starzl TE. Orthotopic liver transplantation with preservation of the inferior vena cava. Ann Surg. 1989;210(5):649-52.

10. Stieber AC. One surgeon's experience with the piggyback versus the standard technique in orthotopic liver transplantation: is one better than the other? Hepatogastroenterology. 1995;42(4):403-5.

11. Sze DY, Semba CP, Razavi MK, Kee ST, Dake MD. Endovascular treatment of hepatic venous outflow obstruction after piggyback technique liver transplantation. Transp lantation.1998;68(3):446-9.

12. Stieber AC, Gordon RD, Bassi N. A simple solution to a technical complication in a "piggyback" liver transplantation. Transplantation. 1997;64(4):654-5.

13. Ducerf C, Rode A, Adham M, De la Roche E, Bizollon T, Baulieux J, et al. Hepatic outflow study after piggyback liver transplantation. Surgery. 1996;120(3):484-7.

14. Cirera I, Navasa M, Rimola A, García-Pagán JC, Grande L, Garcia-Valdecasas JC, et al. Ascites after liver transplantation. Liver Transplant. 2000;6(2):157-62.
15. Massarollo PCB, Brescia MDG, Pereira OI, Beer Jr A, Mies S. Randomized trial comparing hepatic venous outflow obstruction in conventional versus piggyback liver transplantation. J Hepatobiliary Pancreat Surg. 2002;9(Suppl 1):340.

16. Robles R, Parrilla P, Acosta F, Bueno FS, Ramirez P, Lopez J, et al. Complications related to hepatic venous outflow in piggy-back liver transplantation: two versus three-suprahepatic-vein anastomosis. Transplant Proc. 1999;31(6):2390-1.

17. Parrilla P, Sanchez-Bueno F, Figueiras R, Jaurrieta E, Mir J, Margarit C, et al. Analysis of the complications of the piggy-back technique in 1112 liver transplants. Transplantation. 1999;67(9):1214-7.

18. Margarit C, Lázaro JL, Hidalgo E, Balsells J, Murio E, Charco R, et al. Crossclamping of the three hepatic veins in the piggyback technique is a safe and well tolered procedure. Transpl Int. 1998;11(Suppl 1):S248-50.

19. Wind P, Douard R, Cugnenc PH, Chevallier JM. Anatomy of the common trunk of the middle and left hepatic veins: application to liver transplantation. Surg Radiol Anat. 1999;21(1):17-21.

20. Nakamura S, Tsuzuki T. Surgical anatomy of the hepatic veins and the inferior vena cava. Surg Gynecol Obstet. 1981;152(1):43-50.

21. Tannuri U, Mello ES, Carnevale FC, Santos MM, Gibelli NE, Ayoub AA, et al. Hepatic venous reconstruction in pediatric living-related donor liver transplantation - experience of a single center. Pediatr Transplant. 2005;9(3):293-8.

22. Bismuth H, Castaing MD, Sherlock DJ. Liver transplantation by "face-à-face" venacavaplasty. Surgery.1992;111(2):151-5.

23. Perrigault PF, Pageaux GP, Grevy V, Souche B, Gouiry C, Fabre JM, et al. Hemodynamic changes after lateral inferior vena cava clamping in orthotopic liver transplantation. Transplant Proc. 1995; 27(4):2513.

24. Lázaro JL, Charco R, Revhaug A, Murio E, Balsells J, Hidalgo E, et al. Hemodynamics in human liver transplantation with inferior vena cava preservation. Transplant Proc. 1997;29(7):2851-2.

25. Massarollo P, Baía C, Coelho F, Palma T, Rodrigues Júnior AJ, Mies S. Modified piggyback liver transplantation technique using the recipient right and middle hepatic veins. Liver Transpl. 2005;11(7):C15.

26. Calne RY, Williams R. Liver transplantation in man- I, observations on technique and organization in five cases. Br Med J. 1968;4(630):535-40.

27. Salizzoni M, Andorno E, Bossuto E, Cerutti E, Livigni S, Lupo F, et al. Piggyback techniques versus classical technique in orthotopic liver transplantation: a review of 75 cases. Transplant Proc. 1994;26(6):3552-3. 
28. Perkins J. Hepatic venous outflow obstruction after piggyback orthotopic liver transplantation. Liver Transpl. 2006;12(1):159-60.

29. Leonardi LS, Boin IF, Leonardi MI, Tercioti V Jr. Ascites after liver transplantation and inferior vena cava reconstruction in the piggyback technique. Transplant Proc. 2002;34(8):3336-8.

30. Aucejo F, Winans C, Henderson JM, Vogt D, Eghtesad B, Fung JJ, et al. Isolated right hepatic vein obstruction after piggyback liver transplantation. Liver Transpl. 2006;12(5):808-12.

31. Cheng YF, Huang TL, Chen CL, Chen TY, Huang CC, Ko SF, et al. Variations of the middle and inferior right hepatic vein: application in hepatectomy. JClin Ultrasound. 1997;25(4):175-82.
32. Chang RWH, Shan-Quan S, Yen WWC. An applied anatomical study of the ostia venae hepaticae and the retrohepatic segment of the inferior vena cava. J Anat. 1989;164:41-7.

33. Camargo AMSR, Teixeira GG, Ortale JR. Anatomy of the ostia venae hepaticae and the retrohepatic segment of the inferior vena cava. J Anat. 1996;188(Pt 1):59-64.

34. Kozlova EK, Badicov VI, Chemysh AM, Bogushevich MS Modeling blood flow in vessels with changeable caliber for physiology and biophysics courses. Am J Physiol. 1997;272(6 Pt 3):S26-30.

35. Cavalcanti JS, Andrade LP, Moreira IE, Rietra PH, Oliveira ML. A morphological and functional study of the cavo-hepatic junction in the human. Surg Radiol Anat. 1995;17(4):311-4. 